\title{
Expressões da homossexualidade feminina no encarceramento: o significado de se "transformar em homem" na prisão
}

\author{
Maniama Barundki - Pantifía UnivesidadeCatdíica dbRioGrandedbSul, PatoAlege, RioGrandedoSul, Brasil
}

\begin{abstract}
Resumo
Mediante uma perspectiva de gênero, o presente trabalho tem como objetivo investigar as especificidades da homossexualidade feminina no encarceramento. Pela análise do discurso de entrevistas realizadas com duas mulheres encarceradas em uma unidade prisional feminina, trataremos dos significados atrelados ao "se transformar em homem" na prisão. As duas entrevistadas assumiram, dentro do cárcere, posturas, nomes e aparência masculinas e passaram, desde então, a ser reconhecidas por outras internas e pelo próprio staff do presídio como homens. 0 objetivo é entender que tipos de privilégios tais mulheres adquirem como resultado da adoção de padrões de comportamentos tipicamente masculinos. Os resultados atestam que as duas participantes experimentam o statuse os direitos usualmente associados ao masculino, tais como a poligamia e o uso legitimado da força, reproduzindo no espaço intramuros a organização hierárquica que marca as relações heterossexuais na sociedade mais ampla.
\end{abstract}

Palavasdhave Homossexualidade feminina; Gênero; Discurso; Travestismo; Encarceramento.

\section{Expressions of female homosexuality in prison: the meaning of "becoming a man" during incarceration}

\begin{abstract}
From a gender approach, the present work has the goal of investigating the specificities of female homosexuality in prison. From the discursive analysis of interviews conducted with two incarcerated women, we investigate the meanings associated to the experience of "becoming a man" in prison. In prison, the two participants assumed male names and looks, being recognized by other inmates and by the prison staff as men. The goal is to understand the kind of privileges these women acquire as the result of adopting typical male behaviors in prison. Results show that the two participants experience the status and the rights usually associated to men, such as polygamy and the legitimized use of force, reproducing in prison the hierarchical organization that characterize heterosexual relationships in society.
\end{abstract}

Keguads Female homosexuality; G ender; D iscourse; Transvestism; Incarceration.

Expresiones de la homosexualidad femenina en el encarcelamiento: el significado de "transformarse en hombre" en la cárcel

\begin{abstract}
Resumen
A través de una perspectiva de género, el presente estudio tiene como objetivo investigar las especificidades de la homosexualidad femenina en el encarcelamiento. Por medio del análisis del discurso de entrevistas realizadas con dos mujeres encarceladas en una unidad carcelaria femenina, trataremos de los significados vinculados al "transformarse en hombre" en la cárcel. Las dos entrevistadas asumieron, dentro de la cárcel, posturas, nombres y apariencia masculinos y pasaron, a partir de ahí, a seren reconocidas por otras internas y por propio staff de la cárcel como hombres. El objetivo es entender que tipos de privilegios esas mujeres adquieren como resultado de la adopción de patrones de comportamientos típicamente masculinos. Los resultados muestran que las dos participantes experimentan el status y los derechos usualmente asociados al masculino, tales y como la poligamia y el uso legitimado de la fuerza, reproduciendo en el espacio intramuros la organización jerárquica que marca las relaciones heterosexuales en la sociedad más amplia.

Palabras dave Homosexualidad femenina; Género; D iscurso; Travestismo; Encarcelamiento.
\end{abstract}

Em 2008 iniciamos trabalho de campo em um presídio feminino na cidade do Rio de Janeiro. À época, o interesse de nossa pesquisa focava-se na construção da identidade de mulheres sentenciadas pela participação no tráfico de drogas, crime tradicionalmente masculino, mas atualmente marcado pela participação crescente de mulheres (Soares \& Ilgenfritz, 2002).

Durante um ano entrevistamos vinte mulheres presas na instituição. Elas haviam desempenhado funções diversas na atividade, desde a venda de drogas no varejo até a gerência de pontos de venda em suas comunidades. $O$ trabalho de campo reforçou realidades atestadas pela literatura em criminologia, especialmente no que diz respeito ao papel dos homens/ parceiros na iniciação criminosa de mulheres (Steffensmeier \& Allan, 1996; Zaluar, 1993). Por outro lado, o discurso das entrevistadas e 0 trabalho de campo expressavam fenômenos surpreendentes e até então ausentes em nossa revisão bibliográfica.

0 presente artigo tem como objetivo tratar especificamente de um desses fenômenos surpreendentes, a saber, a "transformação" de algumas dessas mulheres em homens dentro da prisão. Embora a homossexualidade feminina nesse cenário nos fosse conhecida e esperada, amplamente atestada por estudos acerca da cultura prisional (Cunha, 1991; Vargas, 2005), 0 fato de algumas dessas mulheres assumirem explicitamente a postura de homens na prisão - usando roupas e adotando nomes masculinos - era um fenômeno que carecia investigação.

As questões que motivaram a produção do atual estudo dizem respeito ao significado da referida "transformação" para algumas mulheres, que passavam 
a ser reconhecidas e tratadas como homens num ambiente exclusivamente feminino. Algumas perguntas que se colocam diante desse fenômeno são: 0 que significa "ser homem" em uma instituição prisional feminina? 0 que motiva a transformação de algumas mulheres para a adoção de padrões de comportamento masculinos na prisão? Que tipo de status está usualmente associado ao "ser homem" neste contexto? $\mathrm{E}$, por fim, 0 que diferencia essas mulheres "transformadas em homens" das outras mulheres que assumem, circunstancialmente ou não, relações afetivas e sexuais com outras mulheres durante 0 período de encarceramento?

No centro das investigações aqui propostas estão questões de gênero. Especificamente nos interessa 0 discurso acerca do poder social e culturalmente percebido como uma propriedade legitimada dos homens. Nesse sentido, assim como ter participado do tráfico de drogas aparentemente aproximava as participantes do "mundo dos homens", ser reconhecida como homem em uma prisão feminina garantia a algumas mulheres os privilégios destinados socialmente aos homens.

Ainda nesta introdução cabe uma breve problematização da expressão "homossexualidade feminina", especialmente quando a presente investigação aborda a experiência de mulheres em uma situação provisória de encarceramento. É fundamental enfatizar que nem todas as mulheres que mantêm relações com outras mulheres na prisão utilizam 0 termo "homossexual" para se autodefinirem. Como nos aponta Weeks (2001, p. 69), "uma boa parte da atividade que ocorre entre pessoas do mesmo sexo nunca é definida como 'homossexual' e não afeta radicalmente o sentido de si de alguém". Portanto, a expressão "homossexualidade feminina" será aqui utilizada para definir a relação estabelecida entre mulheres dentro de uma unidade prisional, independente de tais relações serem definidoras da identidade ou dotadas de sentido apenas dentro do contexto específico do encarceramento.

Antes de tratarmos das especificidades dos dados coletados, fazem-se necessárias algumas palavras acerca da homossexualidade feminina descrita na literatura, bem como da expressão dessa homossexualidade dentro dos muros das instituições carcerárias.

\section{A homossexualidadefeminina}

Sexo e afeto

0 binômio sexo/afeto sempre esteve no centro das discussões acerca da homossexualidade, especialmente como marcadores da distinção entre as práticas homoafetivas masculinas e femininas. Em estudos realizados a partir do atendimento terapêutico a casais homossexuais, Féres-Carneiro (1997) atesta uma maior valorização das dimensões de amizade e companheirismo entre as mulheres, enquanto os homens envolvidos em relações homoafetivas tendiam a valorizar primordialmente a dimensão da sexualidade. Ao analisar as relações de conjugalidade entre mulheres, Heilborn (1992) descreve este tipo de relação como marcada por características semelhantes às presentes na relação social de amizade, tais como 0 companheirismo e o apoio psicológico mútuos. Mott (1987) afirma que o prazer sexual não é a finalidade da relação entre mulheres. Segundo o autor, o que move tais relações é a busca de níveis profundos de comunicação, ternura, carinho e delicadeza.

Entender a relação homossexual como pautada primordialmente no afeto corrobora a imagem do feminino atrelada ao cuidado e ao empenho na manutenção de relações afetivas. Gilligan (1982) sugere que a "ética do cuidado" que caracteriza as mulheres é centrada na atenção às necessidades do outro e à preservação dos relacionamentos afetivos. Também focada no afeto como dimensão essencialmente feminina, Miller (1986) afirma que a mulher constrói a sua identidade servindo aos outros, desenvolvendo a ideia de que a sua vida deve ser guiada pelos desejos, necessidades e vontades daqueles ao seu redor.

Os estereótipos de que mulheres lésbicas são, em geral, monogâmicas e não-promíscuas em suas relações encontram sustentação, portanto, na valorização feminina da esfera afetiva nas relações, em oposição à esfera sexual. Uma vez que a relação entre mulheres é calcada em sentimentos de amor, as mulheres homossexuais tenderiam a estabelecer relações duradouras com uma mesma parceira (Palma \& Levandowski, 2008).

Embora a ênfase na dimensão afetiva como essencialmente feminina pressuponha o (valorizado) afastamento das mulheres lésbicas dos comportamentos sexuais promíscuos que supostamente caracterizam a homossexualidade masculina, esta ênfase resulta também no apagamento da dimensão do prazer sexual como uma possibilidade entre mulheres. É como se o "sexo de verdade" pudesse somente ocorrer com a participação de um homem, porque este deve incluir, necessariamente, a penetração como requisito. Trata-se, portanto, de legitimar 0 caráter normativo das relações heterossexuais (Anjos, 2000). Excluída a possibilidade do prazer sexual entre as mulheres, restaria a elas pautar suas relações no afeto e na cumplicidade.

O s relatos no presente artigo apontam para uma valorização do afeto na relação entre as mulheres encarceradas. O cuidado e carinho femininos são contrapostos, no discurso das participantes, à 
agressividade e violência típica dos homens. A análise dos dados nos falará da violência das figuras masculinas na vida das participantes e do papel desempenhado por essa imagem masculina em suas escolhas amorosas dentro e fora do presídio.

Ao tratarmos especificamente da expressão da homossexualidade para as mulheres encarceradas temos que problematizar a pretensa universalidade da categoria mulher (Butler, 1990; Collins, 1990). Entender as formas de vivências homossexuais para 0 grupo aqui em estudo é assumir que eixos estruturantes da identidade, tais como gênero, classe, cor e orientação sexual, não podem ser entendidos de forma isolada uns dos outros (Acker, 1997; Collins, 1990; Glenn, 1999; West \& Fenstermaker, 1995). Identificarse como homossexual ou estar envolvida em uma relação homoafetiva para uma mulher branca, de classe média, portanto, tem certamente um significado distinto daquele atribuído por mulheres pobres, negras e encarceradas vivenciando experiências semelhantes. O contexto social e cultural das participantes, dentro do qual as suas experiências homossexuais ganham sentido, deve permear a análise dos dados a todo 0 momento.

É somente ao contextualizar o significado do envolvimento afetivo/sexual entre mulheres, circunscrevendo tal experiência em realidades sociais, culturais e econômicas específicas, que podemos desconstruir os binômios homossexualidade feminina/ afeto e homossexualidade masculina/ sexo. A legitimação do desejo sexual feminino, transgredindo a ordem hierárquica que corrobora a dominação do homem ativo sobre a mulher passiva, deve ser analisada em função dos recursos - sociais, culturais, econômicos e linguísticos - que sustentam a subversão da posição feminina dominada (Anjos, 2000).

\section{Atividade e passividade}

0 modelo atividade/ passividade, que reafirma a normatividade das relações heterossexuais, é reportado como mais frequentemente encontrado nas práticas sexuais masculinas do que nas femininas. A ideologia igualitária, apontada por Heilborn (2004) como consequência do movimento feminista, da perda do papel central desempenhado pela família nuclear na estruturação das relações e de uma incipiente liberação homossexual, significou o aparecimento de um modelo simétrico para a homossexualidade. Tal modelo coloca em xeque a tradicional oposição entre 0 masculino e feminino, representada respectivamente pela atividade e passividade na prática sexual.

No que se refere às relações homossexuais, 0 modelo hierárquico que sustenta essa oposição definirá como gay somente aquele indivíduo que é penetrado, que ocupa o papel feminino na relação sexual com seu parceiro. Como ser homossexual se define pelo comportamento sexual passivo, um homem pode manter relações sexuais com outros homens sem perder seu status de homem, desde que não seja por eles penetrado (Fry, 1982). Situado hierarquicamente numa posição inferior, o gay, assim como a mulher, é por definição o passivo na relação com outros homens. Neste sentido, Nunan (2007) ressalta que a homossexualidade seria definida pela distribuição de poder e dominação, não por uma escolha específica de objeto sexual. A autora aponta que no Brasil e nas culturas latinas surgem duas categorias para designar esta relação de dominação e submissão entre casais homossexuais masculinos: o homemé 0 ativo na relação sexual, aquele que penetra e domina a bida, a contraparte passiva e dominada.

A análise do contexto específico em que a valorização dos estereótipos masculinos, tais como a atividade e a agressividade, se expressa é fundamental, porque ela evidencia a interconexão inevitável entre diferentes marcadores identitários, como classe e raça/ cor (Braz, 2007). Portanto, ao analisarmos o discurso das participantes, é necessário que tal análise seja feita a partir dos marcadores específicos que constituem as identidades dessas mulheres. Além do discurso delas trazer a marca do binarismo ativo/ passivo característico de culturas latinas em geral, essas são mulheres pobres, negras e situadas no contexto específico do encarceramento.

Da mesma forma que o feminino é sempre a ameaça do homem (ser homem é, antes de tudo, não ser mulher), a masculinidade definida como possibilidade de penetrar outrem é vetada à mulher. Nas palavras de Torrão Filho (2005, p. 143): "as mulheres lésbicas (...) usurpam um poder que não lhes pertence, e ao qual sequer podem usar, já que são desprovidas dos meios da consumação da masculinidade".

0 homem penetrado é, portanto, desprovido de poder porque se situa na esfera do feminino. Em contraposição, a mulher lésbica, aquela que não se subordina sexualmente ao homem, estabelece a possibilidade de subverter a posição de subordinação destinada às mulheres (Anjos, 2000).

Os dados analisados no presente trabalho demonstrarão como o discurso das entrevistadas reflete o modelo hierárquico no delineamento das relações homossexuais entre as mulheres encarceradas. 0 que nos interessa particularmente é a reedição do modelo passivo vessus ativo nas relações homossexuais entre as mulheres entrevistadas. A assimetria entre os gêneros, naturalmente desconstruída em casais homossexuais 
femininos, é reconstruída a partir da marcação artificial de diferenças entre os pares de mulheres analisados.

\section{A homossexualidadena prisão}

No que diz respeito à escolha homossexual e ao exercício dela dentro do encarceramento, algumas especificidades podem ser tratadas à luz do que denominamos uma "cultura prisional" (Guedes, 2006; Gutierrez \& Almeida, 2008). Sob essa perspectiva, a homossexualidade se caracterizaria como uma ruptura com o universo extramuros e uma reação temporária ao encarceramento. O conceito de "prisionização" designa a adoção das tradições e dos modos de vida da cultura prisional. Dessa forma, o impacto do encarceramento produzia nos internos mudanças semelhantes a qualquer processo aculturativo (Cunha, 1991). Assim como uma nova linguagem, vestuário e gestual, o comportamento homossexual também seria assumido como consequência das possibilidades relacionais disponíveis na prisão. 0 fenômeno do relacionamento entre mulheres nesse contexto, portanto, poderia ser denominado como "homossexualidade situacional".

No contexto da presente discussão, a relação estabelecida entre mulheres na prisão seria exclusivamente justificada pela impossibilidade imposta de relacionamento com o sexo oposto, deixando supor que esta última seria a escolha privilegiada das mulheres no contexto extramuros. Embora possamos compreender o relacionamento homoafetivo dentro do espaço do confinamento como expressão do desejo dessas mulheres, 0 discurso de grande parte das entrevistadas corrobora a imagem do envolvimento circunstancial, motivado exclusivamente pela impossibilidade de uma escolha de objeto normativa.

Considerada como uma ruptura, portanto, a homossexualidade na prisão seria decorrente da privação de contatos heterossexuais e do abandono comumente experimentado pelos internos. No caso das mulheres, a literatura atesta 0 fato de que tal abandono é experimentado com maior intensidade. Enquanto as mulheres de presos mantêm com maior frequência uma rotina de cuidados e de manutenção de seus parceiros na prisão, os homens, em geral, abandonam as suas parceiras quando estas são presas (Lemgruber, 2010).

Mais do que uma reação à carência afetiva imposta pelo encarceramento, no entanto, a associação entre mulheres na prisão parece atender a uma necessidade relacional estruturante do feminino. Acerca do papel das relações afetivas na constituição da identidade feminina, autoras afirmam que a habilidade de estabelecer e manter tais relações encontra-se no centro da subjetividade das mulheres. D essa forma, a mulher se constitui como tal a partir da manutenção de relações significativas com outros. Sob essa perspectiva, as relações amorosas e sexuais com outras mulheres ocupariam para as internas a função de complementaridade usualmente buscada no outro para a constituição da identidade feminina (Gilligan, 1982; Miller, 1986).

Acerca dos contornos assumidos pela cultura prisional feminina, Cunha (1994) nos fala de uma configuração assentada quase que exclusivamente em dois fenômenos: as pseudofamílias e a homossexualidade. Em seus estudos, ambas as configurações foram identificadas como mecanismos de suporte emocional. A configuração do encarceramento feminino se daria, em parte, por uma continuidade com padrões de relacionamento extramuros. As relações pseudofamiliares, em que mulheres ocupariam nas relações com outras os papéis de mães, filhas e irmãs, representariam a importação de modelos relacionais pré-encarceramento. A própria vivência da homossexualidade experimentada em configurações que refletem a organização familiar extramuros, nos deixa pressupor a relevância estrutural do afeto familiar para as identidades femininas.

Os dados analisados demonstrarão as diferentes expressões da homossexualidade feminina presentes no discurso das mulheres encarceradas. A menção à carência e à privação intramuros como motivadoras de comportamentos não normativos é frequente. No entanto, chama-nos a atenção, como já mencionado anteriormente, a forma como a associação afetiva e sexual com outras mulheres é recorrentemente descrita em contraposição às relações vividas com homens fora da prisão. Seja circunstancialmente ou por uma escolha permanente de objeto, a relação com mulheres ocupa na vida dessas prisioneiras um lugar distinto daquele de suas relações heterossexuais, a saber, o lugar do cuidado, da empatia, do "amor verdadeiro". Em ambas as circunstâncias, a expressão da homossexualidade reproduz o lugar de homens e mulheres numa estrutura familiar heterossexual. Portanto, os movimentos de ruptura e continuidade com a realidade extramuros estão presentes nas relações afetivas e sexuais estabelecidas pelas mulheres encarceradas.

É relevante se pensarmos que, apesar de as entrevistadas explicitamente expressarem o caráter nãonormativo de suas relações homossexuais, os padrões e as formas com que sustentam essas relações sejam tão claramente heteronormativos. De certa forma, é como se a transgressão à norma se desse somente, em certa medida, na escolha do parceiro amoroso do mesmo sexo. A maneira como a experiência homossexual é vivida reproduz a normatividade dos papéis socialmente designados a homens e mulheres. 
O conceito de heteronormatividade implica, a partir de uma lógica determinista e biologicista, uma coerência entre sexo, gênero e orientação sexual. D esse modo, segundo Louro (1999), cada sexo somente poderia manter relações afetivas e sexuais com o sexo oposto, sendo a relação "natural" entre homens e mulheres legitimada pela possibilidade de procriação.

\section{“Sapatões" elésicas}

Interessa-nos, na presente investigação, retomar 0 significado de certas categorias adotadas pelos estudos queer ao tratar das peformances de masculinidade de mulheres lésbicas (Halberstam, 1998). Nesta literatura o termo butch é utilizado para denominar as lésbicas masculinas, aquelas "[...] que se sentem mais confortáveis com estilos, códigos e identidades genericamente masculinos do que com aqueles femininos" (Halberstam, 1998, p. 120). Da mesma forma, ao utilizar a expressão "masculinidades femininas", Lacombe (2007) rompe com o binarismo compulsório que associa práticas masculinas somente aos corpos dos homens e práticas femininas aos corpos das mulheres. A expressão denota, portanto, a possibilidade de uma masculinidade de mulheres, entendendo os comportamentos e práticas associadas a essa masculinidade como pefomanes não como expressão da natureza dos homens.

As mulheres cujos dados analisaremos neste trabalho são conhecidas no presídio como "sapatões", em oposição às lésbicas que estabelecem relações supostamente circunstanciais com outras mulheres durante o período de encarceramento. As sapatões, na descrição de outras internas, são mulheres que querem ser homens, que se vestem como homens para adquirir 0 status associado ao masculino. A peformance das sapatões nesse contexto específico, mais do que colocar em xeque o binarismo de gênero, reproduz a assimetria entre homens e mulheres percebida na sociedade mais ampla. Ao se travestirem na prisão, essas mulheres clamam para si os privilégios exclusivos dos homens, tais como a poligamia e a agressividade legitimada.

\section{Método}

Pela a análise do discurso de duas mulheres encarceradas em um presídio feminino, investigaremos os significados atrelados à experiência de "virar homem" na prisão, isto é, de estabelecer relações afetivas e sexuais com outras mulheres ocupando a posição de homens nessas relações.

\section{Participantes}

$\mathrm{Na}$ ocasião das entrevistas, Elisa, que é negra e tinha 25 anos, estava presa há 13 meses e essa era uma das suas várias internações desde a adolescência. Seu prontuário de entrada na unidade prisional traz referências às suas relações familiares, descritas como conflitivas e marcadas por desamparo. 0 pai de Elisa era alcoólatra e a interna relatara, ainda segundo dados do seu prontuário, um sentimento de indiferença em relação à família, resultado da agressão, negligência e rejeição sofridas quando criança.

Elisa é uma figura popular na cadeia. Tem cabelos raspados, usa bermudas de homem com cuecas aparecendo. Adotou um apelido que faz referência ao seu comportamento agressivo e intempestivo, manifestado por brigas constantes com as agentes e por punições dentro da prisão. Tem 21 tatuagens espalhadas pelo corpo (incluindo vários nomes de mulheres); já foi ferida por faca e por arma de fogo no tórax, braço e rosto.

Rosana tinha 26 anos na ocasião da pesquisa, é negra e estava presa há cerca de dois anos quando foi entrevistada. Assim como Elisa, ela tem a cabeça raspada e usa roupas de homens. Curioso enfatizar que a foto em seu prontuário, quando ela foi presa, mostra uma menina de cabelos compridos e roupa justa feminina.

Rosana fala explicitamente do status adquirido ao ser reconhecida como homem na prisão; seu discurso é repleto de referências às vantagens de ser homem em um ambiente feminino. Os poucos dados em seu prontuário falam de diversas entradas em unidades prisionais desde a adolescência. Ela tem 10 tatuagens pelo corpo, uma marca de tiro no ombro esquerdo e uma cicatriz na cabeça. Algumas histórias em torno dessas marcas de violência são relatadas durante as entrevistas e usadas para justificar o envolvimento de Rosana com mulheres dentro da prisão.

Em comum, Elisa e Rosana têm o fato de serem mulheres "transformadas em homem" dentro da unidade prisional. Ambas são reconhecidas e tratadas como homens por colegas de encarceramento e pelo staff do presídio. No jargão interno, Elisa e Rosana são duas "sapatões", ostentando a aparência e os comportamentos legitimados para as "mulheres que viram homens" no encarceramento.

\section{Entrevistas}

Elisa e Rosana foram entrevistadas duas vezes cada uma dentro do período de 12 (doze) meses de coleta de dados na unidade prisional em que estavam presas. A primeira entrevista com cada uma delas foi realizada sem a presença do gravador. 0 objetivo era 
estabelecer algum grau de intimidade com as participantes antes da introdução do gravador.

0 objetivo das entrevistas era investigar as especificidades da criminalidade feminina, compreendendo os fatores familiares, sociais, econômicos, culturais e pessoais que motivavam essas mulheres a se engajarem numa atividade criminosa tradicionalmente masculina como o tráfico de drogas. Embora o foco das entrevistas fossem as trajetórias de vidas das participantes, Elisa e Rosana foram recrutadas justamente por se comportarem, se vestirem e serem tratadas como homens na unidade. Nosso interesse continuava sendo na história de vida delas, porém com o objetivo de entender 0 significado associado ao se "transformar em homem" na prisão.

As entrevistas abertas em profundidade tinham um mínimo de estrutura em seu roteiro e seu fluxo era guiado, primordialmente, pelas entrevistadas. 0 objetivo dessa flexibilidade era possibilitar o contar de histórias sem o constrangimento que um protocolo estruturado de entrevista pode suscitar (Fontana \& Frey, 1994).

As entrevistadas foram informadas do caráter voluntário de sua participação na pesquisa e assinaram o consentimento livre e esclarecido, informando-as dos objetivos e dos procedimentos. A pesquisa foi aprovada pelo Comitê de Ética em Pesquisa da Fundação O swaldo Cruz (Fiocruz/ Rio de Janeiro) e está registrada no CONEP sob 0 número 2872.0.000.031-07.

\section{Análisedos dados}

A partir de uma abordagem discursiva sistêmica (Falmagne, 2004), a análise proposta considera os macro e micro elementos envolvidos no processo de construção do discurso das participantes. Em outras palavras, nos interessa a forma como as entrevistadas reproduzem e transformam os discursos culturais hegemônicos (Edley, 2001; Taylor, 2001) acerca do feminino e do masculino e das relações afetivas/sexuais estabelecidas entre homens e mulheres.

Em relação aos macroelementos, o discurso das entrevistadas é analisado dentro do contexto social, econômico e cultural no qual suas experiências ocorrem e são dotadas de significado. Como enfatizado anteriormente, é apenas a partir de uma análise que considere os macroelementos constitutivos das identidades que podemos tratar da reprodução e transgressão de discursos e comportamentos normativos.

Os microelementos dizem respeito às histórias pessoais de cada participante e as suas estratégias individuais de construção de identidade. Esse nível de análise considera o protagonismo, a intencionalidade e a criatividade como recursos fundamentais para a construção da subjetividade (Assis, 1999; Souza e Silva, 2003).

Quanto à relação entre os dois níveis de análise acima descritos, é óbvio que todo protagonismo é limitado pelo contexto mais amplo de existência do sujeito (Falmagne, 2004). Dessa forma, as escolhas pessoais são, em grande parte, determinadas pela realidade social e econômica dentro da qual o sujeito tem chances limitadas de transgressão.

\section{Resultados e discussão}

Nesta seção os dados das entrevistas com Elisa e Rosana serão analisados com base na perspectiva sistêmica acima sugerida. A análise tratará do significado atribuído pelas participantes aos relacionamentos afetivos e sexuais com mulheres na prisão, bem como da peculiar experiência de se "tornar homem" em uma instituição prisional feminina. Explícita ou implicitamente os discursos de Elisa e Rosana nos falam dos privilégios associados ao masculino, bem como da reprodução de uma lógica heteronormativa nas relações afetivo-sexuais intramuros.

\section{Asfigurasmasalinas}

Nas trajetórias de vida de Elisa e Rosana, as figuras masculinas estão quase que exclusivamente associadas a comportamentos violentos, covardes e negligentes. Desde a descrição de seus pais, passando pelos poucos companheiros homens que tiveram, por policiais e figuras de autoridade, o masculino é, para as duas participantes, associado à violência.

Ao falar da sua vida familiar, Elisa enfatiza em vários momentos a relação conflituosa que sempre teve com o pai, que a rejeitara desde 0 seu nascimento por não acreditar que ela (Elisa) fosse de fato sua filha: "Eu fui rejeitada quando eu nasci pelo meu pai. [...] a minha avó acreditava que eu era filha do meu pai, mas meu pai acreditava que eu era filha do outro".

A mãe, ao ser abandonada pelo pai de Elisa, casase com um traficante que batia frequentemente nela. No trecho a seguir, Elisa fala da raiva ao presenciar as surras que seu padrasto dava em sua mãe, bem como da impotência por não poder protegê-la: "às vezes, quando batia nela eu ficava possessa da vida, entendeu? que eu não podia fazer nada".

Na primeira entrevista com Elisa, ela nos fala da sua única experiência de relacionamento com um homem, aos 15 anos de idade. Foi a partir do relacionamento com esse namorado que Elisa inicia as suas atividades no tráfico, vendendo drogas em pontos 
de venda junto com ele. Ela descreve esse homem como muito violento; durante uma das inúmeras brigas que tiveram, ele lhe deu um tiro no ombro. A partir desse momento, Elisa decide abandoná-lo e não mais se envolver afetivamente com homens. Segundo ela: "quem ama não dá tiro".

Rosana não conheceu o seu pai; foi abandonada pela mãe em um orfanato "quando era pequena" (não sabe precisar a idade). Quando pergunto sobre alguma lembrança de violência física em sua vida, ela mostra uma cicatriz na cabeça e explica que foi resultado de uma tentativa de estupro que sofreu quando vivia nas ruas do Rio de Janeiro. Rosana cita esta e outras experiências de violência praticadas por homens (policiais, colegas de abrigo e meninos de rua) para justificar a sua preferência por relacionamentos afetivos com mulheres: "meninas é mais carinhosas, meninas são menos brutas, homem é covarde, não gosto".

Tanto no discurso de Elisa quanto no de Rosana, as características femininas são descritas em oposição àquelas que marcam 0 masculino. Em suas palavras, mulheres são mais amigas, companheiras, calmas e carinhosas. Apesar da valorização das características "essencialmente" femininas, é interessante notar as múltiplas formas como as duas participantes reproduzem com suas parceiras na prisão a violência sofrida em suas relações com homens, bem como os padrões hierárquicos que marcam as relações heterossexuais extramuros. Elisa, por exemplo, menciona em suas entrevistas as brigas frequentes que tem com a parceira, motivadas principalmente pelo não-cumprimento, por parte desta, das tarefas "domésticas", teoricamente sob sua responsabilidade. Elisa espera encontrar suas roupas limpas e arrumadas e a cela limpa quando retorna do "trabalho" (a atividade de vender sanduíches nas outras celas é dessa forma descrita por ela). Nessas brigas, Elisa diz que bate e morde a parceira quando ela descumpre as funções a ela destinadas.

\section{Ruptura econtinuidade}

Embora Elisa e Rosana enfatizem o rompimento definitivo da participação em relações heterossexuais, ambas reproduzem em seus relacionamentos afetivos e sexuais na prisão os padrões de violência e subjugação que marcaram as suas relações com homens fora do encarceramento. Assim, se o envolvimento exclusivo com mulheres marca uma ruptura com comportamentos e escolhas amorosas anteriores, a reprodução da violência e da dominação experimentada com os homens marca a continuidade, para as participantes, de padrões heteronormativos em suas novas relações.
Elisa tem uma relação estável com Vanessa, com quem divide um beliche em uma cela com outras 48 presas. Em seu discurso, ela converte o espaço da cela no espaço privado do lar. Refere-se à cama dividida com a companheira como "a nossa casa", descrevendo detalhes da sua decoração recentemente realizada. $\mathrm{Na}$ primeira entrevista, ainda sem o uso do gravador, Elisa me convida para ver o papel de parede que elas acabaram de colocar e as almofadas de fuxico e da HelloKitty que decoram a casa delas. Diz, ainda, que as duas cuidam muito da casa, mantendo o piso sempre encerado. Em outra clara referência ao espaço privado da casa reconstruída no cárcere, Elisa diz que "as vizinhas" (outras presas em sua cela) costumam ir até a casa delas à noite para assistirem à TV.

Não é somente na reconstrução física e espacial do lar que Elisa reproduz padrões de organização e relação extramuros. A sua descrição acerca do cotidiano com sua companheira Vanessa nos remete aos padrões tradicionais das relações conjugais heterossexuais. Nessas descrições, cabe à Elisa o papel da provedora, daquela que sai de casa (da cela) para trabalhar, enquanto Vanessa deve cumprir as funções domésticas esperadas das mulheres em uma relação tradicional. Ainda nessa primeira entrevista, Elisa me conta que sai de manhã para a "pista" (gíria que faz alusão ao espaço público da rua) para vender sanduíches. Seu objetivo é sustentar os "luxos" da sua companheira, que faz questão de comprar cosméticos caros, mesmo no encarceramento. As brigas mais freqüentes do casal, segundo Elisa, acontecem quando ela "chega do trabalho" e não encontra a comida pronta ou suas roupas passadas por Vanessa. De diversas formas, portanto, Elisa reproduz, na cadeia, a divisão de gênero que delimita espaços públicos e privados (G iffin, 1994; Saffioti, 2001).

Rosana não tem companheira fixa na prisão. Nas duas ocasiões em que participei de eventos coletivos na instituição, ela estava cercada por mulheres. Sempre vestida com bermudas largas, tênis e boné, Rosana circulava rodeada por essas mulheres. $\mathrm{Na}$ segunda entrevista, questiono o fato dela se vestir de homem na prisão; pergunto especificamente se uma mulher vestida de homem faz mais sucesso com as mulheres naquele contexto. Rosana responde: "E, mais fácil, faz mesmo (mais sucesso), tem mais moral, assim".

Peço para Rosana explicar por que ela acredita que deve "virar homem" para se relacionar com outras mulheres. Em sua resposta, ela reproduz a divisão hierárquica que marca os comportamentos sexuais de homens e mulheres como ativos e passivos, respectivamente: "eu acho feio namorar uma menina e vestida de menina. [...] Porque geralmente elas vão, mas 
fazem as mesmas coisas nas outra. (Quando nos vestimos de homem) só nós que faz tudo".

Ao se "transformar" em homem na prisão, Rosana ganha não somente o privilégio da poligamia (de circular como várias mulheres, sem nenhum cerceamento externo), mas também afirma a sua posição ativa nas relações sexuais estabelecidas com outras mulheres: "nós que faz tudo". Rosana prossegue justificando que não gosta de ser tocada por outras mulheres; é ela quem deve tomar as iniciativas durante a relação sexual, e suas namoradas entendem esta divisão de papéis tacitamente estabelecida.

0 discurso de Rosana reproduz a divisão hierárquica característica das relações afetivas e sexuais entre homens e mulheres na sociedade. A sua transformação em homem na prisão legitima, simultaneamente, sua não-fidelidade e sua exclusiva atividade em relação às mulheres com quem se envolve.

A análise do discurso de Elisa e Rosana atesta, de diversas formas, a reprodução de modelos heteronormativos de relação. Para as duas participantes, a experiência homossexual no cárcere é vivida mediante a manutenção das características que posicionam homens e mulheres em papéis marcadamente distintos em suas relações afetivas e sexuais. Em primeiro lugar, o "transformar-se em homem" parece refletir a crença das participantes de que a relação afetiva e sexual "natural" deve se dar somente entre indivíduos de sexos opostos (Louro, 1999). Embora circunstancialmente mulheres possam se envolver com outras mulheres - como na situação do encarceramento - é a adoção de padrões de comportamento masculinos e a valorização desses padrões que dão a esse envolvimento a legitimidade normativa e concedem às mulheres "transformadas" em homens os privilégios socialmente associados ao masculino.

Reafirmando as ideias de Nunan (2007), segundo as quais a homossexualidade seria definida pela distribuição de poder e dominação - mais do que por uma escolha específica de objeto -, a vivência homossexual no cárcere reflete essa distribuição desigual, em que a atividade, a poligamia, a violência e agressividade são prerrogativas daquelas mulheres reconhecidas como homens. Em contraste, às mulheres não-masculinizadas caberiam as funções de atenção, cuidado e manutenção do espaço doméstico, socialmente consideradas funções femininas (Gilligan, 1982; Miller, 1986).

Como teorizado pelos estudos queer, a homossexualidade feminina no cárcere reflete a existência de diferentes categorias para tratar das pefomances de masculinidade de mulheres lésbicas. No entanto, ao invés de denunciar a limitação do binarismo que associa práticas masculinas somente aos corpos dos homens e práticas femininas aos corpos das mulheres (Lacombe, 2007), a "transformação" de mulheres em homens na prisão parece, sim, legitimar esse mesmo binarismo, associando comportamentos específicos a homens e mulheres.

\section{Considerações finais}

O fenômeno da homossexualidade feminina, tal como vivenciada por Elisa e Rosana, deve ser compreendido a partir da trajetória de vida de cada uma das participantes, bem como do significado adquirido por essa homossexualidade no contexto do encarceramento. Se, por um lado, o envolvimento com mulheres na prisão tem para Elisa e Rosana um significado intimamente relacionado às relações afetivas e sexuais estabelecidas com os homens em suas histórias de vida, a forma de expressão desse envolvimento ganha sentido somente com referência ao contexto de uma unidade prisional feminina.

0 discurso das participantes constrói simultaneamente a homossexualidade como reação à violência masculina e como possibilidade de reprodução dessa mesma violência, numa inversão de papéis em que Elisa e Rosana passam de vítimas à perpetradoras de comportamentos opressores e subjugadores. Portanto, ruptura e continuidade estão presentes nos discursos e nas práticas das participantes que, ao mesmo tempo, afirmam o rompimento com relações heterossexuais e reproduzem com suas parceiras a violência e a hierarquia que caracterizaram suas relações extramuros.

Se "transformar" em homem dentro de uma prisão feminina concede às participantes privilégios tradicionalmente destinados aos homens. Elisa e Rosana têm o direito, legitimado pelas outras internas e pelo próprio staff do presídio, de cobrar de suas companheiras os cuidados com o espaço interno da cela, com o preparo da comida, e de circularem com várias mulheres. Ao serem reconhecidas como homens, as participantes, enfim, experimentam o poder que, em suas histórias de vida, era somente exercido por homens.

\section{Referências}

Acker, J. (1997). Rewriting class, race, and gender: problems of feminist rethinking. Em J. Lorber, B. Hess \& M. Marx Ferree (Eds.), Revisioning gendar (pp. 44-69). Thousand O aks, CA: Sage. 
Anjos, G. (2000). Identidade sexual e identidade de gênero: subversões e permanências. Socidogas 2(4), 274-305.

Assis, S. G. (1999). Tracando caminhos numa soieclade videnta: a vida de jovens infratares e saus imãos não infratores Rio de Janeiro: Fiocruz.

Braz, C. A. (2007). Macho versus macho: um olhar antropológico sobre práticas homoeróticas entre homens em São Paulo. Cadkmos Pagu, 28, 175-206.

Butler, J. (1990). Prdblemas de ĝ̂nera feminismo esubuesão daidantidade Rio de Janeiro: Civilização Brasileira.

Collins, P. H. (1990). Bladk feminist thaught: knowkeege, consciausness, and the pditics of empowement. Nova Iorque: Routledge, Chapman \& Hall.

Cunha, M. I. (1991). A prisão feminima com 'Tlha de Lebos' eescla docime disarsos, representaçás, práticas Lisboa: Centro de Estudos Judiciários.

Cunha, M. I. (1994). Malhas quea relusão tee questões de identidade numa pris̃o feninina. Lisboa: Gabinete de Estudos Jurídico-Sociais.

Edley, N. (2001). Analysing masculinity: interpretative repertoires, ideological dilemmas and subject positions. Em M. Wetherell, S. Taylor \& S. Yates (Eds.), Discurseas data: a guidefor analysis (pp. 189228). London: Sage.

Falmagne, R. J. (2004). O n the constitution of 'self' and 'mind': the dialectic of the system and the person. TheryandPsychdogy, 14(6), 823-846.

Féres-Carneiro, T. (1997). A escolha amorosa e interação conjugal na heterossexualidade e na homossexualidade. Psicloja: Reflexão e Cńtica, 10(2), 351-368.

Fontana, A., \& Frey, J. (1994). Interviewing: the art of science. Em N. Denzin \& Y. Lincoln (Eds.), Handbook of qualitative rearch (pp. 361-376). Thousand O aks: Sage.

Fry, P. (1982). Para ingêsver: identidadeepdítica na altura brasilera. Rio de Janeiro: Zahar.

Giffin, K. (1994). Violência de gênero, sexualidade e saúde. Cadamos deSaúdePúdica, 10(1), 146-155.

Gilligan, C. (1982). Uma va dfeente Rio de Janeiro: Rosa dos Tempos.

Glenn, E. N. (1999). The social construction and institutionalization of gender and race: an integrative approach. Em M. M. Ferree, J. Lorber \& B. Hess (Eds.), Revisioning gender (pp. 3-43). Thousand O aks, CA: Sage.
Guedes, M. A. (2006). Intervenções psicossociais no sistema carcerário feminino. Psicogaja: Ciênia e Prơissãa, 26(4), 558-569.

Gutierrez, G., \& Almeida, M. B. (2008). Cultura e lazer: uma aproximação habermasiana. Lua Nova, 74, 93130.

Halberstam, J. (1998). Female masalinity. Durham and London: Duke University Press.

Heilborn, M. L. (1992). Vida a dois: conjugalidade igualitária e identidade sexual. Em Anais do VIII EncontroNadional deEstudos Populaainais São Paulo, Brasil.

Heilborn, M. L. (2004). Daiséar: gêneroeidantidadesexual emcontextoigualitánio Rio de Janeiro: Garamond.

Lacombe, A. (2007). De entendidas e sapatonas: socializações lésbicas e masculinidades em um bar do Rio de Janeiro. Cademos Pagu, 28, 207-225.

Lembgruber, J. (2010). A dana das haves uma milher no comando das prisães do Rio de Janero Rio de Janeiro: Record.

Louro, G. L. (1999). Pedagogias da sexualidade. Em G. L. Louro (O rg.), O como ecturada peelagogas da sexualidade(pp. 7-34). Belo Horizonte: Autêntica.

Miller, J. B. (1986). Towards a new psychdogy of women Boston: Beacon Press.

Mott, L. (1987). O lesdianismo no Brasil. Porto Alegre: Mercado Aberto.

Nunan, A. (2007). Homossexualidade e discriminaçãa o preconcito sexual intemalizado (Tese de D outorado). Rio de Janeiro: Pontifícia Universidade Católica do Rio de Janeiro, Brasil.

Palma, Y. A., \& Levandowski, D. C. (2008). Vivências pessoais e familiares de homossexuais femininas. Psicoloja emEstudo, 13(4), 771-779.

Saffioti, H. (2001). Contribuições feministas para 0 estudo da violência de gênero. Cademos Pagu, 16, 115-136.

Soares, B., \& Ilgenfritz, I. (2002). Prisioneras vida e vidênaa atrás das grades Rio de Janeiro: G aramond.

Souza e Silva, J. (2003). Por que uns e não atros? Caminhada dejowens pobres para a universidade Rio de Janeiro: 7 Letras.

Steffensmeier, D., \& Allan, E. (1996). Gender and crime: toward a gendered theory of female offending. Annul Reviewof Soidogy, 22, 459-487.

Taylor S. (2001). Locating and conducting discourse analytic research. Em M. Wetherell, S. Taylor \& S. 
Yates (Eds.), Discarseas data: a guidefor analysis(pp. West, C., \& Fenstermaker, S. (1995). D oing difference. 5-48). Londres: Sage. Gender and Socidy, 9(1), 8-37.

Torrão Filho, A. (2005). Uma questão de gênero: onde o masculino e o feminino se cruzam. Cadamos Pagu, 24, 127-152.

Zaluar, A. (1993). Women of gangsters: chronicle of a less-than-musical city. Estudos Feministas, 1(1), 135142.

Vargas, L. O. (2005). Religiosidade: poder e sobrevivência na penitenciária feminina do Distrito Federal. Debates doNER, PatoAlege, 6(8), 21-37.

Weeks, J. (2001). O corpo e a sexualidade. Em G. L.

Reedidbem10/ 06/ 2011 Louro (O rg.), O corpo celurada peclagogas da sexualidade(pp. 35-84). Belo Horizonte: Autêntica. Refomladbem15/ 05/2012 Aprovadoem12/ 06/ 2012

Sobre a autora:

Mariana Barcinski é professora adjunta da Faculdade de Psicologia da Pontifícia Universidade Católica do Rio Grande do Sul (PUC/ RS). O bteve seu título de doutorado na Clark University, em 2006.

Contato com a autora:

Rua Santa Cecília, 1.945/ 301 - CEP: 90420-041. Rio Branco - Porto Alegre-RS.

E-mail: mariana.barcinski@ pucrs.br 